\title{
Evaluating the decision-to-delivery interval in category 1 emergency caesarean sections at a tertiary referral hospital
}

\author{
E Andisha, MB ChB, DA (SA), FCA (SA), MMed; L Cronjé, MB ChB, FCA (SA) \\ Department of Anaesthesia, King Edward VIII Hospital, University of KwaZulu-Natal, Durban, South Africa
}

Corresponding author: E Andisha(andisha_mohamed@yahoo.com)

\begin{abstract}
Background. Caesarean sections (CS) in low- and middle-income countries are still afflicted with high complication rates for both mothers and neonates. A target decision-to-delivery (DDI) interval $\leq 30$ minutes in category 1 emergency CS is the recommended standard of care, although the impact of this target on perinatal outcomes and its practicality is unclear.

Objectives. The purpose of this retrospective study was to evaluate whether a DDI $\leq 30$ minutes was achieved in daily practice and to describe the indications for category 1 emergency CS.

Methods. We conducted a retrospective descriptive study at King Edward VIII Hospital, KwaZulu-Natal, Durban, South Africa, between 1 January and 30 June 2017. Alternate Category 1 cases were selected from an existing departmental database. Relevant data were extracted from standardised institutional booking forms and entered onto a data collection tool.

Results. A total of 153 patients were enrolled in this study; no stillbirths were recorded. Only 5.2\% ( $n=8 / 153)$ of the parturients achieved a DDI $\leq 30$ minutes. The overall median (IQR) DDI was 75.0 (58 - 97) minutes with a range of 13 - 341 minutes. There was no significant difference in the median DDI between neonates with a 5-minute Apgar $\geq 7$ or $<7$. Fetal distress (81.0\%) and placental abruption causing significant antepartum haemorrhage (13.7\%) were the most common indications for CS.

Conclusion. The study demonstrated that achieving a DDI of 30 minutes within the current organisational structure, institutional policies and staffing pattern is very rare. However, units should still benchmark against the internationally recommended 30-minute target as an indicator of unit efficiency and to improve quality of care. Despite absence of correlation between the DDI and the 5-minute Apgar score, unjustified delay from the decision-making to delivery of the baby is not acceptable.
\end{abstract}

S Afr J ObstetGynaecol 2019;25(3):95-99. https://doi.org/10.1796/SAJOG.2019.v25i3.1510

The caesarean section (CS) is an integral component of global maternal healthcare. ${ }^{[1]}$ Recent evidence suggests that the World Health Organization's vision for safe access and quality of care (QoC) for pregnant women and neonates has not yet been attained in Africa. ${ }^{[2,3]}$

Categorising CS may assist in prioritising patients so as to improve outcomes but, although numerous classification systems have been proposed, all have limitations. ${ }^{[4]}$ The four-grade classification system proposed by Lucas et al. ${ }^{[5]}$ is based on grading the urgency of the CS and has been shown to be both consistent and clinically useful. The classification has been endorsed by many professional bodies, including the Royal College of Obstetricians and Gynaecologists (RCOG) ${ }^{[6,7]}$

The time interval from the decision for a CS to be carried out to delivery of the neonate is known as the decision-to-delivery interval (DDI). The RCOG, the National Institute of Clinical Excellence and many other professional organisations recommend a DDI of $\leq 30$ minutes for a category 1 emergency CS. ${ }^{[6-9]}$ DDI is a valuable audit tool, allowing units to test the co-ordination and efficiency of the whole delivery team, especially in those patients who require rapid access to CS if the life of the mother or baby is threatened..$^{[6,10]}$

The main aim of the present study was to evaluate compliance at a tertiary referral hospital in Durban, KwaZulu-Natal, South Africa (SA) with the international standard of care of a DDI in a category 1 (i.e. emergency) CS $\leq 30$ minutes. The secondary objectives were to characterise the primary indications for emergency CS and to document neonatal outcomes; this allowed us to evaluate the efficiency of performance of different teams simultaneously involved in the management of a critical group of patients.

\section{Methods}

We conducted a retrospective descriptive observational study between 1 January and 30 June 2017 at King Edward VIII Hospital, KwaZulu-Natal, Durban, SA. Ethical approval was obtained from the University of KwaZulu-Natal Biomedical Research Ethics Committee (BREC no. BE614/16), with additional hospital and Department of Health (DoH) gatekeeper permissions.

The study included cases of category 1 CS performed for parturients with live babies at term or preterm gestational age. All other categories of CS were excluded, including urgent (category 2), scheduled (category 3 ) and elective (category 4) CS cases. Cases were selected from an existing departmental database which prospectively recorded booking and outcome details for all CSs performed at the institution. The unit adopted Lucas' four-grade classification $^{[5]}$ in 2016 and instituted a standardised CS booking form completed by both the attending obstetrician and anaesthetist.

\section{Outcome variables and data collection}

Category 1 CS was defined as an emergency CS requiring delivery within 30 minutes for any indication that posed an immediate threat to the life of the woman or her fetus, including: fetal distress (FD); placenta praevia causing a significant antepartum haemorrhage 
(APH); cord prolapse; uterine rupture; placental abruption with a live baby causing a significant APH; and maternal cardiac arrest. Fetal condition was assessed by the obstetric team, based on the cardiotocograph (CTG) as 'good,' 'non-reassuring' or 'poor' and recorded on the standardised CS booking form. A 'poor' CTG trace was considered as 'fetal distress'.

Data describing the participants were collected over a period of 6 months. Out of an existing departmental database of 306 category 1 cases, patients included in our study were selected on an alternate basis (i.e. every second case); this resulted in a sample size of 153 cases which was considered a representative sample. The collected data included age, gestational age and the indication for CS. The date and time of decision for CS and date and time of delivery of the baby were recorded and the DDI was defined as the interval between decision and delivery of the baby. Neonatal Apgar scores at 1 and 5 minutes were documented for all neonates, but only the 5-minute scores were used for analysis. Although type of anaesthesia used was recorded, this study did not aim to investigate maternal outcomes or complications relevant to the mode of anaesthesia. All data were extracted by EA, and data entry was verified by LC.

\section{Statistical analysis}

Data were captured and subsequently analysed using SPSS (IBM Corp., USA). The DDI was derived and a 30-minute decisionto-delivery cut-off used to count the percentage of parturients who achieved a DDI $\leq 30$ minutes. Descriptive statistics such as frequencies $(n)$ and percentages (\%) were used to summarise the data, and are presented in tables. Measures of central tendency such as median and measures of dispersion such as interquartile range (IQR) were calculated for numerical variables. For comparisons, the Kruskal-Wallis and Mann-Whitney $U$ test were used as appropriate. A probability level $\leq 0.05$ was considered statistically significant.

\section{Results}

A total 153 patients were enrolled in the study, and no stillbirths were recorded. Approximately half the patients (52.9\%) were aged 20 - 29 years, and $13.1 \%$ of the parturients were teenagers (Table1). The majority of parturients (69.3\%) were at term.

The most common indication for CS was fetal distress (81\%), followed by placental abruption with a live baby, causing significant antepartum haemorrhage (13.7\%). All cases of fetal distress had a 'poor' CTG trace documented.

The overall median (IQR) age of patients was $26(22-32)$ years and median (IQR) gestational age was 38 (36 - 40) weeks. Of the cases enrolled in this study, we found that $94.8 \%$ had DDI intervals exceeding 30 minutes; only $5.2 \%(n=8 / 153)$ of cases achieved a DDI of 30 minutes or less. Owing to the small number of cases that had achieved the $\leq 30$-minute target, and in order to allow comparisons between subgroups, a decision was made to regroup the cases into a target DDI $\leq$ or $>45$ minutes (Table 2 ). There was no significant difference between the median age $(p=0.3)$ or median gestational age ( $p=0.4$ ) between patients in the $>$ or $\leq 45$-minute DDI subgroups. We still found the majority of cases (86.9\%) exceeded a DDI of 45 minutes, with only 20/153 patients being delivered in $\leq 45$ minutes. The majority of cases $(85.6 \%)$ were done under spinal anaesthesia (SA) and the remainder under general anaesthesia (GA).

The median DDI according to the indication for CS and by neonatal 5-minute Apgar is displayed in Table 3. The overall median (IQR) DDI was $75.0(58$ - 97) minutes with a range of $13-341$
Table 1. Characteristics of the study population and indications for emergency caesarean section $(N=153)$

\begin{tabular}{ll}
\hline Variable & $\boldsymbol{n}(\%)$ \\
\hline Age, years & $20(13.1)$ \\
$<20$ & $81(52.9)$ \\
$20-29$ & $52(34.0)$ \\
$\geq 30$ & \\
Gestational age, weeks & $47(30.7)$ \\
$27-36$ & $106(69.3)$ \\
$37-42$ & \\
Indication & $124(81.0)$ \\
Fetal distress & $3(2.0)$ \\
Placenta praevia (causing significant APH) & $3(2.0)$ \\
Cord prolapse & $2(1.3)$ \\
Uterine rupture & $21(13.7)$ \\
Placental abruption & 0 \\
Maternal cardiac arrest & \\
&
\end{tabular}

minutes. Cord prolapse had the shortest median DDI, followed by placental abruption and placenta praevia. The 2 cases of uterine rupture had the longest median (IQR) DDI of 84.5 (29 - 140) minutes. The differences in DDI according to the indications were not significant. When considering the DDI by neonatal outcome, the overall median (IQR) DDI was 74.0 (55 - 93). There was no significant difference in the median DDI between neonates with a 5 -minute Apgar $\geq 7$ or $<7$. Analysis of the distribution of 5-minute Apgar scores according to different DDI cut-off limits (30 minutes, 45 minutes, 75 minutes) also did not show any significant difference.

The DDI according to type of anaesthesia is shown in Table 4. Parturients who underwent GA had a median (IQR) DDI of 61 (37 - 72) minutes which was statistically shorter than the DDI of 77 (59 -100) minutes of those who underwent SA $(p=0.006)$. When we compared neonatal outcomes according to type of anaesthesia, we found that the SA group had statistically better 5-minute Apgars $(p=0.004)$.

Although it was not a primary outcome to compare indications for emergency CS between patients done under spinal and patients done under GA, this study has shown that only 2/124 of fetal distress patients had GA. The indications for CS in the other 20 patients done under GA were: $2 / 2$ cord prolapse, $3 / 3$ placenta praevia, 14/21 placental abruption and $1 / 2$ uterine rupture. These figures may indicate a potentially poorer-condition maternal and fetal population in the GA group.

\section{Discussion}

The main finding of our study was that only 1 in 20 parturients who were booked for an emergency category 1 CS achieved a target DDI $\leq 30$ minutes. The median DDI was 75 minutes, with a range of 13 - 341 minutes. Both these findings differ significantly from current international standards.

In 1989, the American College of Obstetricians and Gynecologists Committee on Professional Standards recommended that in the case of emergency CS, the DDI should not exceed 30 minutes, and similar recommendations have been issued by other international professional bodies. ${ }^{[6,8,9,11]}$ The former recommendation was based on the premise that maternal and neonatal outcomes will be worse 


\begin{tabular}{|c|c|c|}
\hline & $\begin{array}{l}\text { DDI } \leq 45 \text { minutes } \\
(N=20), n(\%)^{*}\end{array}$ & $\begin{array}{l}\text { DDI }>45 \text { minutes } \\
(N=133), n(\%)\end{array}$ \\
\hline \multicolumn{3}{|l|}{ Variable } \\
\hline Age (years), median $(\mathrm{IQR})^{\dagger}$ & $24.5(21.1-29.5)$ & $27.0(22-32)$ \\
\hline Gestational age (weeks), median (IQR) ${ }^{\ddagger}$ & $37.0(34-40)$ & $38.0(36-40)$ \\
\hline \multicolumn{3}{|l|}{ Indication } \\
\hline Fetal distress & $10(8.1)$ & $114(91.9)$ \\
\hline Placenta praevia (causing significant APH) & 0 & $3(100)$ \\
\hline Cord prolapse & $2(66.7)$ & $1(33.3)$ \\
\hline Uterine rupture & $1(50.0)$ & $1(50.0)$ \\
\hline Placental abruption & $7(33.3)$ & $14(66.7)$ \\
\hline Maternal cardiac arrest & 0 & 0 \\
\hline Total & $20(13.1)$ & $133(86.9)$ \\
\hline \multicolumn{3}{|c|}{ 5-minute Apgar score (for term babies $\geq 37$ weeks) $(n=106)$} \\
\hline$\geq 7$ & $10(10.3)$ & $88(89.8)$ \\
\hline$<7$ & $2(25.0)$ & $6(75.0)$ \\
\hline Total & $12(11.4)$ & $94(88.6)$ \\
\hline \multicolumn{3}{|l|}{ Type of anaesthesia } \\
\hline GA & $8(36.4)$ & $14(63.6)$ \\
\hline SA & $12(9.2)$ & $119(90.8)$ \\
\hline Epidural & 0 & 0 \\
\hline Total & $20(13.1)$ & $133(86.9)$ \\
\hline \multicolumn{3}{|l|}{ Type of operation } \\
\hline Emergency CS & $19(13.0)$ & $127(87.0)$ \\
\hline Emergency CS and BTL & $1(14.3)$ & $6(85.7)$ \\
\hline Total & $20(13.1)$ & $133(86.9)$ \\
\hline
\end{tabular}

\section{Table 3. Median DDI according to indications and 5-minute Apgar score}

\begin{tabular}{|c|c|c|c|}
\hline Variable & $n(\%)$ & Median DDI (min) & $\mathrm{IQR}$ \\
\hline \multicolumn{4}{|l|}{ Indication $^{\star}$} \\
\hline Fetal distress & $124(81.0)$ & 77.0 & $59.5-98$ \\
\hline Cord prolapse & $3(2.0)$ & 36.0 & $13-100$ \\
\hline Uterine rupture & $2(1.3)$ & 84.5 & $29-140$ \\
\hline Placental abruption & $21(13.0)$ & 62.0 & $37-85$ \\
\hline Maternal cardiac arrest & 0 & - & - \\
\hline Overall & $153(100)$ & 75.0 & $58-97$ \\
\hline \multicolumn{4}{|l|}{ 5-minute Apgar score (for term babies $\geq 37)^{\dagger}$} \\
\hline$<7$ & $8(7.5)$ & 73.0 & 31.5 \\
\hline$\geq 7$ & $98(92.5)$ & 74.0 & 40.0 \\
\hline Total & $106(100)$ & 74.0 & 38.0 \\
\hline
\end{tabular}

should this time be exceeded. ${ }^{[12,13]}$ Despite these recommendations, there is little evidence for this benchmark and there is considerable debate as to whether a DDI $\leq 30$ minutes is a realistic and feasible target to aim for in daily practice or whether outcomes would be improved if this DDI is achieved..$^{[10,14-17]}$

Evidence from high-income countries (HICs) suggests that the 30-minute DDI in emergency CS is achievable. ${ }^{[18,19]}$ However, this is not a universal finding and an overall success rate of $79 \%$ may be a more more realistic assessment ${ }^{[17]}$ and, even in HICs, targeting a DDI of 30 minutes in category 1 patients is difficult to achieve in clinical practice. ${ }^{[14,20]}$ A prospective study from SA by le Riche et al ${ }^{[21]}$ found that only $20 \%$ of patients delivered by CS at a tertiary centre within the 30-minute timeframe. In the present study, it was shown that only $5.2 \%$ of patients delivered within the benchmark time; this finding is similar to other low- and middle-income countries (LMICs), suggesting that compliance with the current standard of care is rarely achievable in daily practice. ${ }^{[21-26]}$

If a target of $\leq 30$ minutes is not feasible, is there another DDI target which is more achievable, but does not adversely affect maternal and fetal outcomes? Studies have suggested $\leq 45$ minutes 
Table 4. Type of anaesthesia and type of operation $v$. median DDI

\begin{tabular}{|c|c|c|c|}
\hline Variable & $n(\%)$ & $\begin{array}{l}\text { Median DDI } \\
\text { (minutes) }\end{array}$ & $\mathrm{IQR}$ \\
\hline \multicolumn{4}{|l|}{ Type of anaesthesia* } \\
\hline GA & $22(14.4)$ & 61.0 & $37-72$ \\
\hline SA & $131(85.6)$ & 77.0 & $59-100$ \\
\hline Epidural & 0 & & \\
\hline \multicolumn{4}{|l|}{ Type of operation ${ }^{\dagger}$} \\
\hline Emergency CS & $146(95.4)$ & 75.0 & $58-98$ \\
\hline Emergency CS and BTL & $7(4.6)$ & 69.0 & $50-96$ \\
\hline \multicolumn{4}{|c|}{$\begin{array}{l}\mathrm{DDI}=\text { decision-to-delivery interval; } \mathrm{IQR}=\text { interquartile range; } \mathrm{GA}=\text { general anaesthesia; } \mathrm{SA}= \\
\text { spinal anaesthesia; } \mathrm{CS}=\text { caesarean section; BTL }=\text { bilateral tubal ligation. } \\
\text { *Type of anaesthesia: two-sample Wilcoxon rank-sum (Mann-Whitney) test, } p=0.006 . \\
\text { 'Oppration: two-sample Wilcoxon rank-sum (Mann-Whitney), } p=0.7 .\end{array}$} \\
\hline
\end{tabular}

is acceptable; ${ }^{[27]}$ however, even with this more lenient target, we still found only 1 in 7 parturients who delivered within that timeframe.

There are studies that have found that a DDI $\leq 75$ minutes is an achievable target and neonatal outcomes are not significantly worse if 75 minutes are not exceeded..$^{[7,16,28]}$ The study by le Riche et al. ${ }^{[21]}$ found a median DDI of 48 minutes for Category $1 \mathrm{CS}$, within the 75-minute benchmark. The median DDI achieved in our study was 75 minutes, i.e. $50 \%$ of cases exceeded the 75 -minute threshold. Our findings are worse than those of le Riche, but many LMICs show DDIs far in excess of 75 minutes. ${ }^{[22,26]}$

Irrespective of the ongoing debate about whether achieving a DDI $\leq 30$ minutes is practical and appropriate or not, it is still recommended to follow and to benchmark against the international regulations issued by professional bodies, respected authorities and medicolegal bodies. Unacceptable reasons for delay should be documented and quality improvements be undertaken. Furthermore, unless there is a clear reason, the delivery of babies in cases of emergency CS should not be delayed to the extent reflected in our results.

There are certain clinical situations which will require a much quicker DDI than in others while, in other situations, undue haste to achieve a short DDI may introduce its own risks with the potential for maternal and neonatal harm. ${ }^{[6]}$ In two separate studies performed in Europe, Mackenzie et al. ${ }^{[13]}$ and Kolas et al. ${ }^{[29]}$ found that the indication for emergency CS had a significant influence on the DDI; this could be explained by prioritisation of certain emergency cases over others, depending on indications, i.e. not all Category 1 cases are equally urgent. Some influence on DDI was seen in our present study, depending on the indications for the emergency CS, but findings were inconsistent and not significant, implying a lack of true prioritisation.

The results of our study showed that GA compared with SA for emergency CS was associated with a significantly shorter median DDI (of $\sim 15$ minutes). It is very hard to ascribe cause and effect, as we do not have sufficient data, but we surmise that cases labelled as very high risk were transferred to theatre more quickly and were therefore also more likely to receive GA, i.e. a quicker transfer rather than the GA per se were contributory to a shorter DDI. Findings from studies by Dunphy et al., ${ }^{[30]}$ Tuffnell et al., ${ }^{[31]}$ Hein et al. ${ }^{[19]}$ and Mackenzie et al. ${ }^{[13]}$ showed a similar influence on DDI by a chosen type of anaesthesia. Although the present study demonstrated a shorter DDI in the GA group, neonatal outcomes were better in the SA group. This finding is similar to those in the literature and may reflect either that a GA is chosen in situations where the parturient or fetus is more compromised or that SA is beneficial. ${ }^{[13]}$ Although it was not the primary focus of the study, and having small numbers, the finding that the majority of GAs were performed for sicker patients may support these speculative reasons.

There is currently little scientific evidence confirming preference of GA over spinal anaesthetic, or that the delay from performing the spinal anaesthetic causes a worse neonatal condition at birth. Further research is required to answer these questions and, until clear guidance is found, we emphasise the importance of communication between the anaesthetic team and the obstetric team to identify the true degree of urgency of the operation and making a case-by-case decision on inter alia the mode of anaesthesia to choose.

The present study assessed neonatal outcome at birth as a function of DDI. Cord blood analysis was not available for the neonates, and therefore the 5-minute Apgar was used as a surrogate measure of neonatal outcome. This approach also allowed comparison with other similar studies. We found it very difficult to draw conclusions on the impact of the DDI on neonatal outcome, owing to the scanty number of cases performed within the international standard of $\geq 30$ minutes. Furthermore, we found no difference in the distribution of 5-minute Apgar scores at 45-minute or 75-minute DDI cut-offs, and no difference in median DDI in relation to an Apgar $\geq 7$ or $<7$ at 5 minutes. These findings suggest minimal impact of DDI on neonatal outcomes in our study; this is contrary to the findings of Thomas et $a l .{ }^{[16]}$ and Radhakrishnan et al. ${ }^{[26]}$ who found neonatal outcomes were worse at a longer DDI, but were in keeping with the results from other studies. ${ }^{[13,14,22]}$ Prospective trials lacking confounders and using cord blood analysis are necessary to confirm the relation between DDI and neonatal outcome.

Based on results from studies conducted in HICs, factors that enhance the ability of units to achieve a target DDI $\leq 30$ minutes are: improving the communication between the different teams; establishing protocols to deal with emergency cases; better staffing workflow and levels; and improving unit facilities. ${ }^{[12,18,19]}$ The present study did not investigate the causes of delay; therefore it is difficult to comment on this subject. However, in the hospital where our study was conducted, factors such as the availability of only one operating room for non-elective CSs, a large volume of complex referred cases, a long waiting list for CS and a high CS rate may have contributed to not achieving the international recommended DDI.

\section{Study strengths and limitations}

The present study is retrospective in its nature, which may limit validity. The data were collected from only one centre, moreover a tertiary referral hospital, from which it follows that results may not be generalisable to other facilities in the province.

The 5-minute Apgar score used for evaluation of neonatal outcome is a subjective tool and a crude measure of outcome and may therefore not be a reliable indicator of neonatal clinical status at delivery nor a predictor for long-term neurological outcome. ${ }^{[23]}$ On the other hand, the 5-minute Apgar score has been used in several comparable studies, therefore allowing comparisons to be drawn with our study.

King Edward VIII Hospital is a tertiary referral hospital receiving a complex spectrum of pathology and has a CS rate of close to $50 \%$ (departmental statistics) and it is also a student and registrar training centre linked to the University of KwaZulu-Natal. Conclusions and 
potential remedial actions from the study could therefore positively affect a large community of patients and trainees.

\section{Conclusion}

This study demonstrated that achieving a DDI of 30 minutes within the current organisational structure, institutional policies and staffing patterns is very rare. However, units should still benchmark against the internationally recommended 30-minute target as an indicator of unit efficiency and to improve quality of care. Despite absence of correlation between DDI and the 5-minute Apgar score, unjustified delay from decision-making to delivery of the baby is not acceptable. The present study could be considered as an initiative for other large and comprehensive studies to provide information specifically on causes of delay and thus strategies that improve standards of care, and further to evaluate a more exact distinction of urgency to establish the correct DDI.

Acknowledgements. We thank Prof. Thomas (Ted) Sommerville and Dr Pragasan Gopalan for their invaluable assistance and guidance.

Author contributions. EA and LC designed the study and jointly wrote the manuscript. Data collection was done by EA.

Funding. None.

Conflict of interest. None.

1. O’Neill KM, Greenberg SL, Cherian M, et al. Bellwether procedures for monitoring and plannin essential surgical care in low-and middle-income countries: Caesarean delivery, laparotomy, an treatment of open fractures. World J Surg 2016;40(11):2611-2619. https://doi.org/10.1007/s00268016-3614-y

2. 2Bishop D, Dyer RA, Maswime S, et al. Maternal and neonatal outcomes after caesarean delivery in the African Surgical Outcomes Study: A 7-day prospective observational cohort study. Lancet Glob Health 2019;7(4):e513-e522. https://doi.org/10.1016/S2214-109X(19)30036-1

3. Tunçalp O, Were W, MacLennan C, et al. Quality of care for pregnant women and newborns - the WHO vision. BJOG 2015;122(8):1045-1049. https://doi.org/10.1111/1471-0528.13451

4. Torloni MR, Betran AP, Souza JP, et al. Classifications for cesarean section: A systematic review. PLoS ONE 2011;6(1):e14566. https://doi.org/10.1371/journal.pone.0014566

5. Lucas D, Yentis S, Kinsella S, et al. Urgency of caesarean section: A new classification. J Royal Soc Med 2000;93(7):346-350. https://doi.org/10.1177/014107680009300703

6. Royal College of Obstetricians and Gynaecologists(RCOG). Classification of Urgency of Caesarean Section - A Continuum of Risk (Good Practice No. 11). https://www.rcog.org.uk/globalassets/ documents/ guidelinesgoodpracticell classificationofurgency.pdf (accessed 29 June 2017).

7. Soltanifar S, Russell R. National Institute for Health and Care Excellence (NICE) guidelines for caesarean section, 2011 update: Implications for the anaesthetist. Int J Obstet Anesth 2012;21(3):264-272. htss://doi.org/10.1016/j.ijoa.2012.03.004

8. Grace L, Greer RM, Kumar S. Perinatal consequences of a category 1 caesarean section at term. BM] Open 2015;5(7):e007248. https://doi.org/10.1136/bmjopen-2014-007248

9. The Royal Australian and New Zealand College of Obstetricians and Gynaecologists. Joint RANZCOG/ ANZCA Position Statement on the Provision of Obstetric Anaesthesia and Analgesia Services. 2015. http://www.anzca.edu.au/documents/wpi-14-2014-position-statement-on-the-provision-of.pd (accessed 29 June 2017)
10. Royal College of Obstetricians and Gynaecologists (RCOG). The National Sentinel Caesarean Section Audit Report. https://www.rcog.org.uk/globalassets/documents/guidelines/...audit/nscs_audit.pdf (accessed 29 May 2019).

11. National Institute for Health and Care Excellence. Clinical Guidelines for Emergency CS (CG132 Cesarean Section). http://www.guidance.nice.org.uk/CG132 (accessed 23 July 2017).

12. Sayegh I, Dupuis O, Clement H, Rudigoz R. Evaluating the decision-to-delivery interval in emergency caesarean sections.Eur J Obstet Gynecol Reprod Biol 2004;116(1):2833. https://doi.org/10.1016/j. ejogrb.2004.01.032

13. MacKenzie I, Cooke I. What is a reasonable time from decision-to-delivery by caesarean section? Evidence from 415 deliveries. BJOG 2002;109(5):498-504. https://doi.org/10.1111/j.14710528.2002.01323.x

14. Helmy $\mathrm{W}$, Jolaoso A, Ifaturoti $\mathrm{O}$, Afify S, Jones $\mathrm{M}$. The decision-to-delivery interval for emergency caesarean section: Is 30 minutes a realistic target? BJOG 2002;109(5):505-508. https://doi.org/10.1111/ j.1471-0528.2002.00491.x

15. MacKenzie I, Cooke I. Prospective 12 month study of 30 minute decision to delivery intervals for 'emergency' caesarean section. BMJ 2001;322(7298):1334-1335. https://doi.org/10.1136 bmj.322.7298.1334

16. IThomas J, Paranjothy S, James D. National cross sectional survey to determine whether the decision to delivery interval is critical in emergency caesarean section. BMJ 2004;328(7441):665. https://doi. org/10.1136/bmj.38031.775845.7C

17. Tolcher MC, Johnson RL, El-Nashar SA, West CP. Decision-to-incision time and neonatal outcomes: A systematic review and meta-analysis. Obstet Gynecol 2014;123(3):536-548. https://doi.org/10.1097/ AOG.0000000000000132

18. Lim Y, Shah M, Tan H. Evaluation of surgical and anaesthesia response times for crash caesarean sections - an audit of a Singapore hospital. Ann Acad Med Singapore 2005;34(10):606.

19. Hein A, Thalen D, Eriksson Y, Jakobsson JG. The decision to delivery interval in emergency caesarean sections: Impact of anaesthetic technique and work shift. F1000Research 2017;6:1977-1990. https:// doi.org/10.12688/f1000research.13058.1

20. Spencer MK, MacLennan AH. How long does it take to deliver a baby by emergency caesarean section? Aust N Z J Obstet Gynaecol 2001;41(1):7-11. https://doi.org/10.1111/j.1479-828X.2001.tb01287.x

21. Le Riche H, Hall D. Non-elective caesarean section: How long do we take to deliver? J Trop Ped 2005;51(2):78-81. https://doi.org/10.1093/tropej/fmh082

22. Chukwudi OE, Okonkwo CA. Decision-delivery interval and perinatal outcome of emergency caesarean sections at a tertiary institution. Pak J Med Sci 2014;30(5):946-950. https://doi.org/10.12669/ pjms. 305.5470

23. Kumoyo M. Decision delivery interval for emergency caesarean sections. Master's Dissertation Lusaka: University of Zambia, 2015. http://dspace.unza.zm/handle/123456789/4358

24. Habib HA. Emergency caesarean section turnaround time and its effect on maternal and newborn health outcomes. Master's Dissertation. Nairobi: University of Nairobi, 2010. http://erepository.uonbi. acke:8080/xmlui/handle/123456789/13758

25. Fyneface-Ogan S, Mato C, Enyindah C. Decision to delivery interval: Reasons for delay. J Med Biomed Res 2009;8(1):72-78

26. Radhakrishnan G, Yadav G, Vaid NB, Ali H. Factors affecting 'decision to delivery interval' in emergency caesarean sections in a tertiary care hospital: A cross sectional observational study. Int J Reprod Contracep Obstet Gynecol 2016;2(4):651-656. https://doi.org/10.5455/2320-1770. ijrcog20131231

27. South Australia Department of Health. Standards for the Management of Category One Caesarean Section in South Australia. https://www.sahealth.sa.gov.au/wps/wcm/connect.pdf (accessed 3 June 2017)

28. Homer CS, Catling-Paull C. Safe timing for an urgent caesarean section: What is the evidence to guide policy? Aust Health Rev 2012;36(3):277-281. https://doi.org/10.1071/AH11059

29. Kolås T, Hofoss D, Øian P. Predictions for the decision-to-delivery interval for emergency cesarean sections in Norway. Acta Obstet Gynecol Scand 2006;85(5):561-566. https://doi. org/10.1080/00016340600589487

30. Dunphy B, Robinson J, Shell O, Nicholls J, Gillmer M. Caesarean section for fetal distress, the interval from decision to delivery, and the relative risk of poor neonatal condition. J Obstet Gynaecol 1991;11(4):241-244. https://doi.org/10.3109/01443619109027807

31. Tuffnell DJ, Wilkinson K, Beresford N. Interval between decision and delivery by caesarean sectionare current standards achievable? Observational case series. BMJ 2001;322(7298):1330-1333. https:// doi.org/10.1136/bmi.322.7298.1330

Accepted 8 February 2020 